\title{
CONCENTRAÇÃO FOLIAR DE NUTRIENTES EM CULTIVARES DE Coffea arabica L. SOB ESPAÇAMENTOS ADENSADOS
}

\author{
Foliar nutrient contents in cultivars of Coffea arabica L. at condensed spacings
}

\author{
Humberto Silva Augusto², Herminia Emilia Prieto Martinez ${ }^{3}$, Nélson Ferreira Sampaio ${ }^{4}$, \\ Cosme Damião Cruz ${ }^{5}$, Adriene Woods Pedrosa ${ }^{6}$
}

\begin{abstract}
RESUMO
Os plantios adensados de café proporcionam melhor reciclagem de nutrientes e conseqüentemente reduzem a perda de nutrientes do solo por erosão, lixiviação e oxidação da matéria orgânica. Avaliaram-se as influências de diferentes espaçamentos na concentração de macro e micronutrientes em folhas de cafeeiro das cultivares IAC 44, IAC 99, MG 1192, Katipó, MG 6851 e UFV 3880. Ao início do experimento o solo foi arado para incorporação do calcário. As mudas foram plantadas em covas de 0,30 x 0,30 x 0,40 m, espaçadas entre si em 0,75 m na fileira. Na adubação de plantio aplicou-se $200 \mathrm{~g}$ de Fosfato Natural de Araxá, $50 \mathrm{~g}$ de Superfosfato Simples por cova, e 15 dias após o plantio $2 \mathrm{~L} /$ cova de esterco em cobertura. As demais adubações foram realizadas segundo o recomendado para a cultura do café. O delineamento foi em blocos casualizados num esquema fatorial $6 \times 4$ (seis cultivares $\mathrm{x}$ quatro espaçamentos), com seis repetições. As parcelas foram compostas por quatro fileiras de 4,50 m de comprimento, espaçadas entre fileiras em 1,0;1,5;2,0 e 2,5 m. Amostras de folhas foram retiradas aos 21 e 34 meses para avaliação dos teores foliares de macro e micronutrientes. $\mathrm{O}$ adensamento não influenciou na concentração de nutrientes nas folhas aos 21 meses após o plantio, mas influenciou as concentrações foliares de $\mathrm{P}, \mathrm{K}$ e Mg aos 34 meses após o plantio.
\end{abstract}

Termos para indexação: Coffea arabica L., adensamento, macronutrientes, micronutrientes.

\section{ABSTRACT}

Coffee-tree condensed plantings provide reduction in the loss of the soil nutrients by erosion, lixiviation and oxidation of the organic matter, and even increase nutrient recycling. This experiment aimed evaluates the influence of different spacing among rows on the nutrient foliar contents of coffee-tree varieties, and was performed in randomized blocks with 24 treatments and six replications. The employed varieties IAC 44, IAC 99, MG 1192, Katipó, MG 6851 and UFV 3880 were planted with a spacing of 0,75 m among plants and 1,0;1,5;2,0 and 2,5m among rows. Each plot was composed of 4 rows of 4,50 m of length, being the evaluations realized in two inner rows. At the beginning of the experiment the soil was plowed for incorporation of the limestone. The seedlings were planted in holes of $0,30 \times 0,30 \times 0,40 \mathrm{~m}$. At the planting each hole received 200g of Natural Phosphate of Araxá, 50g of Simple Super phosphate. 15 days after the planting each plant received $2 \mathrm{~L} /$ hole of cattle manure. The reminded fertilizations were made according to the usual procedures for coffee-plant orchards. Samples of leaves were collected and analyzed to determine the macro and micronutrient contents 21 and 34 months after planting. It was concluded that the condensed planting influenced the foliar contents of $\mathrm{P}, \mathrm{K}$ and $\mathrm{Mg} 34$ months after the panting.

Index terms: Coffea arabica L., condensed, macronutrientes, micronutrientes, trail analysis.

(Recebido em 15 de maio de 2006 e aprovado em 13 de dezembro de 2006)

\section{INTRODUÇÃO}

A erosão, lixiviação e oxidação da matéria orgânica são processos rápidos que contribuem para acidificação contínua e aceleração da degradação da fertilidade do solo, tornando-se um dos maiores problemas dos plantios de cafeeiros em espaçamentos largos, ou com baixa população de plantas por unidade de área. No entanto, o adensamento é um sistema conservacionista que protege o solo, diminui as perdas por erosão e lixiviação, diminui a oxidação da matéria orgânica, proporcionando melhor manejo dos resíduos e melhorando o sistema de reciclagem de nitrogênio (N) e outros nutrientes (PAVAN \& CHAVES, 1996).

O sistema adensado proporciona maior aproveitamento da água e nutrientes, diminuindo as perdas e melhorando a eficiência do uso de fertilizantes (PAVAN \& CHAVES, 1994), contribuindo ainda, na melhoria da capacidade produtiva do solo através de aumentos do $\mathrm{pH}$, $\mathrm{Ca}, \mathrm{Mg}, \mathrm{K}, \mathrm{P}$ e C orgânico (PAVAN \& CHAVES, 1996; SANTOS, 1999), estabilidade de agregados, retenção de água e diminuição de Al tóxico (PAVAN \& CHAVES, 1996).

\footnotetext{
'Extraído da disertação de doutorado apresentada pelo primeiro autor à Universidade Federal de Viçosa (UFV), Viçosa, MG. Financiado parcialmente pela Prefeitura Municipal de Ervália.

2Doutor pelo Departamento de Fitotecnia - Universidade Federal de Viçosa/UFV - Avenida Peter Henry Rolfs - 36570-000 - Viçosa, MG

${ }^{3}$ Doutora - Departamento de Fitotecnia - Universidade Federal de Viçosa/UFV - Avenida Peter Henry Rolfs - 36570-000 - Viçosa, MG - herminia@ufv.br ${ }^{4}$ Doutor - EMBRAPA Rondônia - Br 364, Km 5,5 - 78900-970 - nelson@cpafro.embrapa.br

${ }^{5}$ Doutor - Departamento de Biologia Vegetal - Universidade Federal de Viçosa/UFV - Avenida Peter Henry Rolfs - 36570-000 - Viçosa, MG cdcruz@ufv.br

6Bacharel - Universidade Federal de Viçosa/UFV - Avenida Peter Henry Rolfs - 36570-000 - Viçosa, MG - awoodsp@yahoo.com.br
} 
No plantio adensado, as exigências minerais não são proporcionais ao aumento da população devido à utilização mais eficiente dos fertilizantes, em razão do maior número de raízes por volume de solo, havendo maior proteção das raízes absorventes superficiais e pela menor lixiviação dos minerais (RENA \& MAESTRI, 1986).

Nos espaçamentos adensados, onde há melhor aproveitamento dos fertilizantes, a dose a ser aplicada por planta é menor e a recomendação é definida por área (RENA et al., 1998). Porém, Barros et al. (1996) verificaram que os níveis nutricionais até a primeira safra para plantios adensados, não devem ser reduzidos e a aplicação do adubo deve ser por planta, ou por metro de sulco, independentemente do espaçamento utilizado, para que haja melhor desenvolvimento inicial da planta.

A análise foliar aliada à análise do solo, permite avaliar com maior eficiência o estado nutricional da lavoura. A faixa crítica de referência para a interpretação dos resultados de análise foliar varia com as condições climáticas, exposição do terreno, tipo de solo, disponibilidade de água e nutrientes, interação entre nutrientes do solo e da planta, idade da cultura, produção pendente, volume e eficiência do sistema radicular, declividade do terreno, cultivo prévio, ataque de pragas e doenças, uso de defensivos ou fertilizantes foliares e outras práticas de manejo que influenciam a composição mineral dos tecidos vegetais (MARTINEZ et al., 1999).

Alguns fatores genéticos podem proporcionar diferenças nas concentrações dos teores foliares dos nutrientes minerais, indicando que entre cultivares e entre linhagens existe maior ou menor eficiência de absorção, de translocação ou de utilização de nutrientes pela planta.

Garcia (1980) observou que a cultivar Mundo Novo retira mais zinco $(\mathrm{Zn})$ do solo que a Catuaí, e esta por sua vez retira mais que a Catimor, ocorrendo o contrário com o Boro (B). Souza et al. (1997) também encontraram maiores taxas de crescimento das mudas de Catuaí com a metade da dose de Zn, necessária para maiores taxas de crescimento das cultivares Mundo Novo e Icatu, indicando maior eficiência de utilização desse nutriente pela primeira cultivar.

Pereira (1999) observou maiores teores de nitrogênio $(\mathrm{N})$ na cultivar Catuaí, em relação às linhagens de UFV 2983 e UFV 3880, na fase de muda, enquanto a última linhagem apresentou os maiores teores de potássio (K). No mesmo ensaio aos dois anos e meio após o plantio a cultivar Catuaí apresentou os maiores teores foliares de N e K e a linhagem UFV 2983 mostrou-se mais eficiente no uso desses nutrientes.

Souza (1999) verificou melhor eficiência de utilização do enxofre (S) para a cultivar MG 1192 do que para a Catuaí, ambas de porte baixo, porém para as de porte alto dependendo do tipo de solo, o coeficiente de utilização biológica das duas cultivares citadas não diferiu.

Neste trabalho, avaliou-se a influência dos espaçamentos em relação aos teores foliares de macro e micronutrientes em diferentes cultivares de café.

\section{MATERIAL E MÉTODOS}

O experimento foi instalado na Unidade de Difusão de Tecnologia em Café, em Ervália - MG, onde as mudas de Coffea arabica L. das cultivares Catuaí Vermelho (IAC 44 e IAC 99), Rubi (MG 1192), Katipó, Oeiras (MG 6851) e Catimor (UFV 3880), foram plantadas em covas de $0,30 \mathrm{x}$ 0,30 x 0,40 m, no tipo de solo Latossolo Vermelho-Amarelo distrófico, em março/abril de 1996.

No preparo do solo realizou-se a calagem na área total conforme o critério da Saturação de Bases, proposto pela CFSEMG (1989), havendo posterior incorporação do calcário com arado. A adubação de plantio constou de uma mistura de $200 \mathrm{~g}$ de Fosfato Natural de Araxá com 50 g de Superfosfato Simples por cova, sendo aplicado ainda 15 dias após o plantio $2 \mathrm{~L}$ de esterco de curral por cobertura em cada cova.

O delineamento foi em blocos ao acaso com 6 repetições, sendo cada repetição composta por 24 tratamentos compreendendo o fatorial $6 \times 4$, com 6 cultivares (IAC 44, IAC 99, MG 1192, Katipó, MG 6851 e UFV 3880) de café e 4 espaçamentos entre fileiras. As parcelas foram constituídas de 4 fileiras de $4,50 \mathrm{~m}$ de comprimento, espaçadas de 1,0;1,5; 2,0 e 2,5 m, com espaçamento entre plantas na fileira fixado em $0,75 \mathrm{~m}$, totalizando 24 plantas por parcela. Considerou-se como plantas úteis da parcela 4 plantas competitivas, sem falhas ao redor e com bom vigor vegetativo entre as 8 plantas centrais.

Adubações de cobertura foram realizadas no primeiro ano (1996) com três parcelas contendo $20 \mathrm{~g}$ de $\mathrm{N}$ e $15 \mathrm{~g}$ de $\mathrm{K}_{2} \mathrm{O}$ por planta, e complementadas com 3 adubações foliares com micronutrientes ( $\mathrm{Zn}, \mathrm{B}$ e $\mathrm{Cu}$ a 0,5\%). No segundo ano (1997) aplicaram-se $45 \mathrm{~g}$ de N e $45 \mathrm{~g} \mathrm{~K}_{2} \mathrm{O}$ por metro linear (MATIELLO et al., 1994). Já no terceiro e quarto anos, 1998 e 1999, respectivamente, a adubação foi realizada por módulos (1 módulo = 10 sacas pendentes/ ha), com base na carga pendente, aplicando-se três parcelas com $20 \mathrm{~kg} / \mathrm{ha} /$ módulo de $\mathrm{N}$, e $25 \mathrm{~kg} / \mathrm{ha} /$ módulo de $\mathrm{K}_{2} \mathrm{O}$. $\mathrm{O}$ $\mathrm{P}_{2} \mathrm{O}_{5}$ foi aplicado na dose de $20 \mathrm{~kg} / \mathrm{ha} /$ módulo no primeiro parcelamento (MALAVOLTA, 1996).

Para análise nutricional foram coletadas aos 21 e 34 meses após o plantio amostras de folhas do 3ํ e 4 pares a partir do ápice dos ramos, com retirada de uma folha por 
ramo, de quatro ramos por planta, localizados no terço médio da copa (BATAGLIA \& DECHEN, 1986).

\section{RESULTADOS E DISCUSSÃO}

Aos 21 meses após o plantio das cultivares de café, não houve efeito significativo de espaçamentos e nem da interação cultivares $\mathrm{x}$ espaçamentos nos teores foliares de nutrientes, indicando não haver diferença na competição por nutrientes em função das densidades de plantio. Não houve diferença entre cultivares nos teores de $\mathrm{K}, \mathrm{Ca}, \mathrm{Zn}$, $\mathrm{Fe}$ e B, mas houve diferença para os nutrientes $\mathrm{N}, \mathrm{P}, \mathrm{S}, \mathrm{Mg}$ e Cu (Tabela 1).

As cultivares IAC 44, MG 1192, MG 6851 e UFV 3880 apresentaram teores de $\mathrm{K}$ dentro da faixa crítica de referência, e as cultivares IAC 99 e Katipó um pouco acima da faixa crítica de referência. Pereira (1999) observou maiores teores foliares de K na cultivar de UFV 2237 que nas linhagens de UFV 2983 e UFV 3880, apesar de constatar alta eficiência de utilização na UFV 2983, quando este era escasso.

Em todas Cultivares os teores de Ca e $\mathrm{Zn}$ ficaram abaixo da faixa crítica de referência, enquanto o de B ficou dentro da faixa considerada adequada. Os teores de Fe das cultivares MG 1192, Katipó e MG 6851 ficaram acima da faixa crítica de referência, e os das cultivares IAC 44, IAC 99 e UFV 3880 dentro da faixa crítica de referência.

A cultivar MG 1192 apresentou os maiores teores foliares de $\mathrm{N}$ e P, não diferindo da IAC 44 em relação ao N e da IAC 99, Katipó e MG 6851, em relação ao P, indicando melhor eficiência de absorção e/ou translocação desses nutrientes, porém todas as cultivares apresentaram teores de $\mathrm{N}$ próximos ao limite superior, e de $\mathrm{P}$ próximos ao limite inferior da faixa crítica de referência. Pereira (1999) não observou diferença entre os teores foliares de N nas linhagens de UFV 2983, UFV 3880 e UFV 2237, mas constatou melhor eficiência de utilização para a UFV 2983, semelhantemente ao que ocorreu ao P; e em relação ao K não houve diferença entre cultivares.

As cultivares IAC 99 e MG 6851 apresentaram os maiores teores de $\mathrm{S}$, e as cultivares IAC 44 e UFV 3880 os teores mais baixos, porém todas as cultivares apresentaram teores abaixo da faixa crítica de referência. Souza (1999) verificou que houve diferença entre cultivares nos teores foliares de $\mathrm{S}$, dependendo do tipo de solo e da quantidade de $\mathrm{S}$ disponível no solo. Neste trabalho as cultivares IAC 99 e MG 6851 apresentaram melhor eficiência de utilização de S e não diferiram de MG 1192 e Katipó.

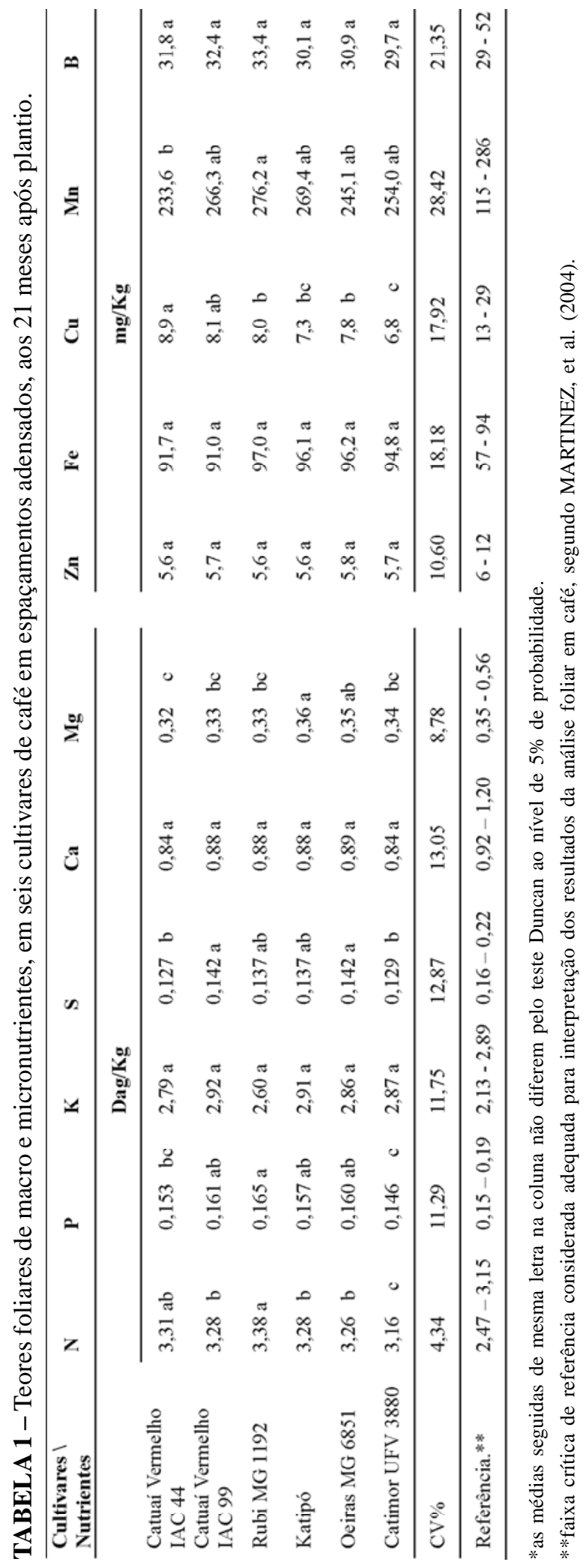


Os maiores teores foliares de $\mathrm{Mg}$ foram encontrados nas cultivares Katipó, que não diferiu da MG 6851. Os teores foliares das cultivares Katipó e MG 6851 ficaram dentro do intervalo da faixa de referência, e os teores das cultivares IAC 44, IAC 99, MG 1192 e UFV 3880 abaixo da faixa crítica de referência.

Em relação ao $\mathrm{Cu}$, todas as cultivares apresentaram teores abaixo da faixa crítica de referência, sendo que as cultivares IAC 44 e IAC 99 apresentaram os maiores teores, e Katipó e a UFV 3880 os menores; indicando que as cultivares IAC 44 e IAC 99 possuem maior capacidade de absorção e/ou translocação desse nutriente em caso de deficiência.

Os teores de Mn encontraram-se dentro da faixa crítica de referência. Só houve diferença entre os teores da MG 1192 (mais alto) e a IAC 44 (mais baixo).

Aos 34 meses após o plantio os teores foliares de $\mathrm{P}, \mathrm{Mg}, \mathrm{Ca}, \mathrm{Zn}, \mathrm{Cu}$ e $\mathrm{B}$ não foram afetados pelos espaçamentos para as cultivares estudadas. Os teores foliares de Fe não sofreram efeito de espaçamento nem de cultivares (Tabela 2).

Aos 34 meses após o plantio os teores de $\mathrm{P}$ diminuíram em relação à amostragem anterior, ficando abaixo da faixa crítica de referência. Tal fato pode ser devido provavelmente, ao maior volume do sistema radicular presente em área exterior à cova de plantio onde estava concentrado o adubo fosfatado. Na comparação entre cultivares verificou-se que IAC 44 apresentou o maior teor de P, embora não diferindo da cultivar IAC 99, e a UFV
3880 e a MG 6851, os menores teores, indicando melhor capacidade de absorção e/ou translocação pelas primeiras cultivares quando esse nutriente encontra-se pouco disponível no solo (Tabela 2).

Aos 34 meses, os teores de $\mathrm{Ca}$ e $\mathrm{Mg}$ aumentaram consideravelmente em relação à amostragem anterior para todas as cultivares, provavelmente devido ao maior tempo de reação do calcário no solo e realização de uma calagem superficial. Os teores de Ca ficaram dentro da faixa crítica de referência. Apenas o teor de Ca das cultivares MG 6851 e MG 1192 ficaram acima e abaixo desse valor, respectivamente, indicando sua maior e menor eficiência de absorção e/ou translocação de Ca. Os teores de $\mathrm{Mg}$ ficaram dentro do intervalo de referência para todas as cultivares. A Katipó, a MG 6851 e a UFV 3880 foram as cultivares que apresentaram os maiores teores, sendo novamente a MG 1192 mais a IAC 44 as cultivares que apresentaram os menores teores foliares de $\mathrm{Mg}$.

Quanto ao Zn, os teores praticamente não se alteraram em relação à amostragem anterior, porém nesta última o teor da cultivar MG 6851 foi superior ao das demais, igualando-se apenas ao da IAC 44, indicando que houve a maior eficiência da MG 6851 em absorver e/ou translocar esse nutriente, quando esse é pouco disponível no solo.

A cultivar UFV 3880 apresentou os menores teores foliares de $\mathrm{Cu}$ e de $\mathrm{B}$. De um modo geral, para todas as cultivares esses teores aumentaram em relação à amostragem anterior, ficando dentro do intervalo de referência.

TABELA 2 - Teores foliares de P, Ca, Mg, Zn, Fe, Cu e B, em seis cultivares de café e quatro espaçamentos entre fileiras, aos 34 meses após o plantio.

\begin{tabular}{llllllllll}
\hline Cultivar\ Nutriente & $\mathbf{P}$ & $\mathbf{C a}$ & $\mathbf{M g}$ & $\mathbf{Z n}$ & $\mathbf{F e}$ & $\mathbf{C u}$ & $\mathbf{B}$ \\
\hline Catuaí Vermelho IAC 44 & $0,143 \mathrm{a}$ & $1,12 \mathrm{ab}$ & 0,41 & $\mathrm{de}$ & $6,2 \mathrm{ab}$ & $111,1 \mathrm{a}$ & $13,4 \mathrm{a}$ & $47,4 \mathrm{ab}$ \\
Catuaí Vermelho IAC 99 & $0,137 \mathrm{ab}$ & $1,13 \mathrm{ab}$ & $0,44 \mathrm{~cd}$ & $5,4 \mathrm{~b}$ & $111,1 \mathrm{a}$ & $13,8 \mathrm{a}$ & $48,6 \mathrm{a}$ \\
Rubi MG 1192 & $0,130 \mathrm{bc}$ & $0,98 \mathrm{c}$ & 0,40 & $\mathrm{e}$ & $5,5 \mathrm{~b}$ & $113,9 \mathrm{a}$ & $13,2 \mathrm{a}$ & $46,4 \mathrm{ab}$ \\
Katipó & $0,129 \mathrm{bc}$ & $1,13 \mathrm{ab}$ & $0,49 \mathrm{ab}$ & $5,5 \mathrm{~b}$ & $110,2 \mathrm{a}$ & $13,2 \mathrm{a}$ & $44,5 \mathrm{ab}$ \\
Oeiras MG 6851 & $0,121 \mathrm{c}$ & $1,22 \mathrm{a}$ & $0,50 \mathrm{a}$ & $6,6 \mathrm{a}$ & $107,6 \mathrm{a}$ & $14,0 \mathrm{a}$ & $42,1 \mathrm{~b}$ \\
Catimor UFV 3880 & $0,122 \mathrm{c}$ & $1,07 \mathrm{bc}$ & $0,47 \mathrm{abc}$ & $5,7 \mathrm{~b}$ & $102,6 \mathrm{a}$ & 11,1 & $\mathrm{~b}$ & 36,4 & $\mathrm{c}$ \\
\hline CV\% & 11,55 & & 14,81 & 14,69 & 8,42 & 19,34 & 15,69 & 19,38 \\
\hline Referência** & $0,15-0,19$ & $0,92-1,2$ & $0,35-0,56$ & $6-12$ & $57-94$ & $13-29$ & $29-52$ \\
\hline
\end{tabular}

*as médias seguidas de mesma letra na coluna não diferem pelo teste Duncan ao nível de 5\% de probabilidade.

**faixa crítica de referência para interpretação dos resultados da análise foliar em café, segundo Martinez et al. (2004). 
Os teores de nutrientes aos 34 meses após o plantio, que apresentaram interação significativa de cultivares com espaçamentos foram nitrogênio $(\mathrm{N})$, potássio $(\mathrm{K})$, enxofre $(\mathrm{S})$ e manganês $(\mathrm{Mn})$, conforme o Tabela 3.

As concentrações foliares de $\mathrm{N}$ não sofreram efeito de cultivares quando o espaçamento entre linhas foi de 2,5 $\mathrm{m}$, entretanto, nos espaçamentos de 1,$0 ; 1,5$ e $2,0 \mathrm{~m}$ destacaram-se as cultivares IAC 44, IAC 99 e MG 6851, respectivamente, enquanto que a cultivar UFV 3880 apresentou nessas condições as menores concentrações foliares de $\mathrm{N}$.

Para o S também não houve diferença expressiva entre as cultivares no espaçamento de $2,5 \mathrm{~m}$. Nos espaçamentos 2,0; 1,5 e 1,0 m destacaram-se IAC 99, Katipó e MG 6851, respectivamente. De todo modo tanto para N, quanto para $\mathrm{S}$ os teores foliares estiveram próximos do limite superior da faixa de suficiência para todas as cultivares e espaçamentos.

A diferença de resposta ao $\mathrm{K}$ entre cultivares diante das vantagens proporcionadas pelo adensamento ficou mais restrita ao espaçamento de $1,0 \mathrm{~m}$, no qual a cultivar IAC 44 e a Katipó apresentaram os maiores teores, junto com a MG 6851 e a IAC 99. No espaçamento de 1,5 m não houve diferença significativa entre cultivares e nos demais espaçamentos (2,0 e 2,5 m) essas diferenças foram menos evidentes. Os teores de $\mathrm{K}$ ficaram próximos ao limite inferior do faixa crítica de referência, com valores bem abaixo dos obtidos na amostragem aos 21 meses.

Os teores foliares de Mn não apresentaram diferenças marcantes entre cultivares em todos os espaçamentos, e no espaçamento de $1,0 \mathrm{~m}$ não foi encontrada diferença significativa. Porém os teores mais baixos foram observados para a cultivar Katipó, sendo mais evidentes nos espaçamentos de 1,0 $\mathrm{m}, 1,5 \mathrm{~m}$ e 2,0 m, demostrando um potencial de seleção para tolerância à toxidez de Mn. Os teores foliares de Mn no geral mantiveram-se nos mesmos níveis anteriormente avaliados.

Aos 34 meses após o plantio, houve efeito de espaçamentos apenas para os teores dos macronutrientes $\mathrm{P}, \mathrm{K}, \mathrm{S}$ e $\mathrm{Mg}$, não se observando esse efeito com os teores de micronutrientes. Para o $\mathrm{S}$ não se obteve bom ajuste dos componentes linear, quadrático ou cúbico para concentração foliar em função do espaçamento adotado entre linhas.

Conforme a Figura 1a verificou-se que houve comportamento diferenciado das cultivares para os teores foliares de P, influenciado pelo nível de adensamento. Esses teores aumentaram linearmente para as linhagens de Catuaí e para a cultivar MG 1192. Já para a Katipó diminuiu de forma quadrática, com o aumento do espaçamento, atingindo um mínimo em torno do espaçamento de 2,0 m. Para as cultivares UFV 3880 e para a MG 6851 não houve efeito de espaçamento. Pavan \& Chaves (1996) observaram aumentos da disponibilidade de P no solo com o aumento da densidade de plantio, fato justificado através do aumento do grau de micorrização das plantas e do aumento de $\mathrm{pH}$ que por sua vez diminui a complexação com óxidos de Fe e Al.

Na Figura 1b observou-se que somente as cultivares Katipó e MG 6851 apresentaram efeito de espaçamento sobre os teores foliares de K. Na cultivar Katipó o teor de $\mathrm{K}$ diminuiu de forma quadrática com o aumento do espaçamento na entrelinha do café, atingindo um valor mínimo, no espaçamento de 2,0 m. $\mathrm{Na}$ cultivar MG 6851 aumentou linearmente com o adensamento. Aumentos na disponibilidade de K no solo sob cultivos adensados de cafeeiro são justificados por Pavan \& Chaves (1996) através do aumento da eficiência da reciclagem de nutrientes e menores perdas por lixiviação.

A Figura 1c ilustra o efeito de espaçamento sobre os teores de Mg. Somente as cultivares Katipó e MG 6851 tiveram efeito de adensamento sobre os teores de Mg. Porém com o aumento do espaçamento, os teores foliares de Mg para essas duas cultivares aumentaram linearmente, fato contrário ao que aconteceu com os teores de K, indicando um antagonismo entre esses dois nutrientes. Porém o $\mathrm{Ca}$ e $\mathrm{Mg}$ foram fornecidos pela calagem em área total, e nos maiores espaçamentos há maior área por unidade de raízes e conseqüentemente um maior reservatório desses nutrientes, justificando o incremento nos teores foliares de $\mathrm{Mg}$ com o aumento de espaçamento. Não foi observado o mesmo efeito para os teores foliares de $\mathrm{Ca}$, indicando que nessa situação essas cultivares poderiam possuir afinidade para absorver ou translocar proporcionalmente, mais $\mathrm{Mg}$ que o $\mathrm{Ca}$. 
TABELA 3 - Teores foliares de N, K, S e Mn, em seis cultivares de café e quatro espaçamentos entre fileiras, aos 34 meses após o plantio.

\begin{tabular}{|c|c|c|c|c|c|c|c|c|}
\hline Nutrientes & & $\mathbf{N}$ & $(\mathrm{dag} / \mathrm{Kg})$ & & & $\mathbf{K}$ & (dag/Kg) & \\
\hline Cultivares\Espaçamentos & 1,0 & 1,5 & 2,0 & 2,5 & 1,0 & 1,5 & 2,0 & 2,5 \\
\hline Catuaí Vermelho IAC 44 & $3,37 \mathrm{a}$ & $3,30 \mathrm{ab}$ & $3,13 \mathrm{ab}$ & $3,27 \mathrm{a}$ & $2,13 \mathrm{a}$ & $1,95 \mathrm{a}$ & $1,96 \mathrm{a}$ & $1,82 \mathrm{ab}$ \\
\hline Catuaí Vermelho IAC 99 & $3,19 \mathrm{abc}$ & $3,55 \mathrm{a}$ & $3,26 \mathrm{ab}$ & $3,25 \mathrm{a}$ & $1,98 \mathrm{ab}$ & $1,95 \mathrm{a}$ & $1,93 \mathrm{ab}$ & $2,02 \mathrm{a}$ \\
\hline Rubi MG 1192 & $3,08 \mathrm{abc}$ & $3,07 \quad b c$ & $3,09 \mathrm{ab}$ & $3,26 \mathrm{a}$ & 1,79 bc & $1,93 \mathrm{a}$ & $1,83 \mathrm{ab}$ & $1,70 \quad b$ \\
\hline Katipó & $3,07 \mathrm{bc}$ & $3,11 \mathrm{bc}$ & $2,96 \mathrm{~b}$ & $3,22 \mathrm{a}$ & $2,12 \mathrm{a}$ & $1,77 \mathrm{a}$ & $1,68 \mathrm{~b}$ & $1,79 \mathrm{ab}$ \\
\hline Oeiras MG 6851 & $3,23 \mathrm{ab}$ & 3,21 bc & $3,37 \mathrm{a}$ & $2,99 \mathrm{a}$ & $2,03 \mathrm{ab}$ & $1,83 \mathrm{a}$ & $1,78 \mathrm{ab}$ & $1,63 \mathrm{~b}$ \\
\hline Catimor UFV 3880 & $2,93 \quad \mathrm{c}$ & $3,00 \quad \mathrm{c}$ & $2,96 \mathrm{~b}$ & $3,23 \mathrm{a}$ & $1,63 \mathrm{c}$ & $1,84 \mathrm{a}$ & $1,99 \mathrm{a}$ & $1,89 \mathrm{ab}$ \\
\hline $\mathrm{CV} \%$ & 7,43 & & & & 10,90 & & & \\
\hline Referência & $2,47-3,15$ & & & & $2,13-2,89$ & & & \\
\hline Nutrientes & & $\mathbf{S}$ & $(\mathrm{dag} / \mathrm{Kg})$ & & & Mn & $(\mathrm{mg} / \mathrm{Kg})$ & \\
\hline Cultivares\Espaçamentos & 1,0 & 1,5 & 2,0 & 2,5 & 1,0 & 1,5 & 2,0 & 2,5 \\
\hline Catuaí Vermelho IAC 44 & $0,179 \quad \mathrm{c}$ & $0,185 \mathrm{~b}$ & $0,195 \mathrm{bc}$ & $0,200 \mathrm{ab}$ & $231,3 \mathrm{a}$ & $213,1 \mathrm{ab}$ & $304,1 \mathrm{a}$ & $265,2 \mathrm{ab}$ \\
\hline Catuaí Vermelho IAC 99 & 0,193 bc & $0,201 \mathrm{ab}$ & $0,244 \mathrm{a}$ & $0,213 \mathrm{ab}$ & $279,8 \mathrm{a}$ & 297,1 a & $337,2 \mathrm{a}$ & 319,8 a \\
\hline Rubi MG 1192 & $0,204 \mathrm{ab}$ & $0,197 \quad b$ & $0,214 \quad b$ & $0,206 \mathrm{ab}$ & $292,3 \mathrm{a}$ & $233,7 \mathrm{ab}$ & $192,7 \quad b$ & $286,4 \mathrm{ab}$ \\
\hline Katipó & 0,197 bc & $0,219 \mathrm{a}$ & $0,194 \mathrm{bc}$ & $0,213 \mathrm{ab}$ & $195,0 \mathrm{a}$ & $194,1 \quad b$ & $177,8 \quad b$ & $261,3 \mathrm{ab}$ \\
\hline Oeiras MG 6851 & $0,221 \mathrm{a}$ & $0,201 \mathrm{ab}$ & $0,209 \mathrm{~b}$ & $0,220 \mathrm{a}$ & 249,6 a & $298,2 \mathrm{a}$ & $295,1 \mathrm{a}$ & $217,2 \quad b$ \\
\hline Catimor UFV 3880 & 0,198 bc & $0,190 \mathrm{~b}$ & $0,188 \quad \mathrm{c}$ & $0,198 \mathrm{~b}$ & $261,7 \mathrm{a}$ & $280,3 \mathrm{a}$ & $340,1 \mathrm{a}$ & $238,9 \mathrm{ab}$ \\
\hline $\mathrm{CV} \%$ & 10,43 & & & & 29,08 & & & \\
\hline Referência & $0,16-0,22$ & & & & $115-286$ & & & \\
\hline
\end{tabular}

*as médias seguidas de mesma letra na coluna não diferem pelo teste Duncan ao nível de 5\% de probabilidade.

**faixa crítica de referência para interpretação dos resultados da análise foliar em café, segundo Martinez et al. (2004). 


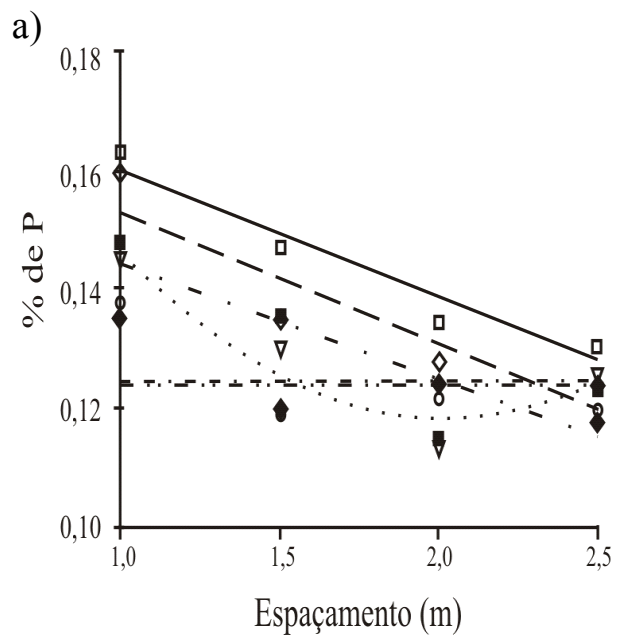

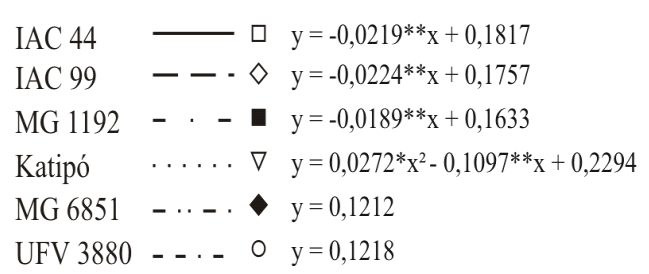

b)
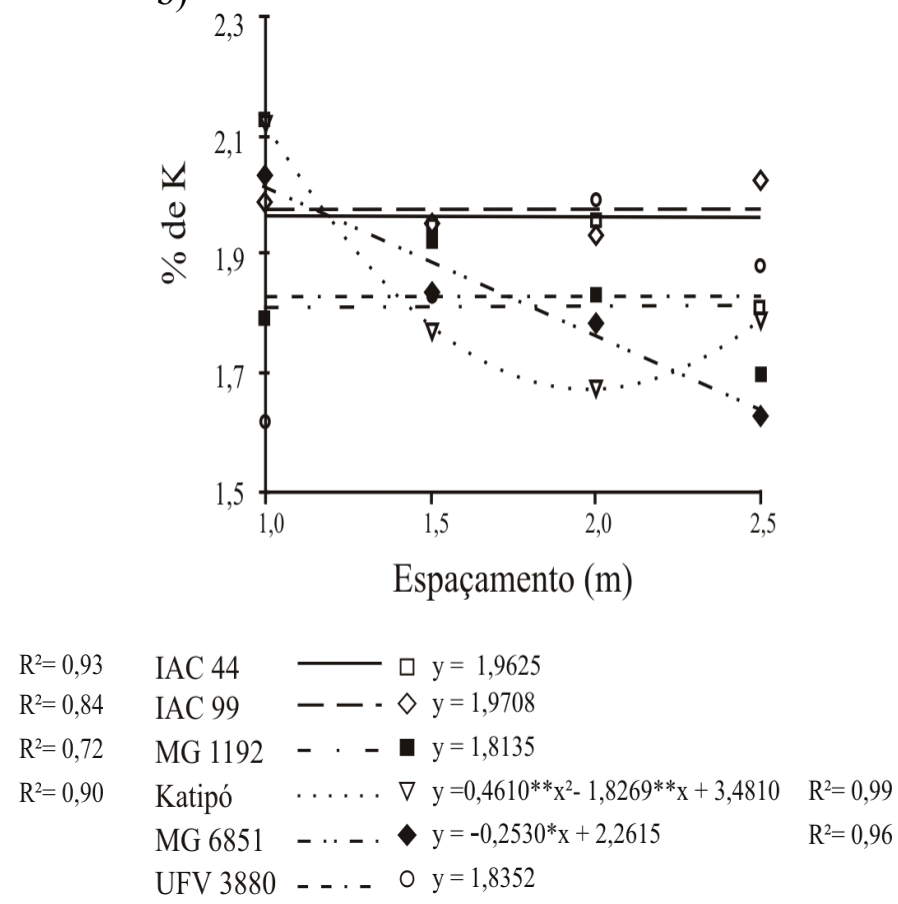

c)


FIGURA 1 - Teor foliar de fósforo (a), de potássio (b) e magnésio (c) em seis cultivares de café (Coffea arabica L.), aos 34 meses após o plantio, em função do espaçamento entre fileiras. 


\section{CONCLUSÕES}

A diferenciação dos teores foliares de nutrientes nas cultivares é um indicativo para seleção de materiais com melhor capacidade de absorção e/ou translocação de nutrientes e melhor tolerância à toxidez de Mn.

$\mathrm{O}$ adensamento pode evidenciar diferenças entre cultivares de café na capacidade de absorção ou translocação dos macronutrientes N, K e S.

Verificou-se, aos 34 meses após o plantio, que o adensamento influencia os teores foliares de $\mathrm{P}, \mathrm{K} \mathrm{e} \mathrm{Mg}$ dos cafeeiros.

O espaçamento não afetou a absorção do $\mathrm{N}$ para as cultivares IAC 44, IAC 99, MG 1192 e UFV 3880; do P para as cultivares MG 6851 e UFV 3880 e do K para as cultivares IAC 44, IAC 99, MG 6851 e UFV 1192.

\section{REFERÊNCIAS BIBLIOGRÁFICAS}

BARROS, U. V.; SANTINATO, R.; MATIELLO, J. B.; BARBOSA, C. M. Níveis nutricionais - NPK Ca Mg S Zn e B - na implantação do cafeeiro em sistemas super adensado, adensado e largo, em solo LVh na Zona da Mata-MG. In: CONGRESSO BRASILEIRO DE PESQUISAS CAFEEIRAS, 22., 1996, Águas de Lindóia, SP. Resumos dos Trabalhos Apresentados... Rio de Janeiro: MAA/PROCAFÉ, 1996. p. 121-123.

BATAGLIA, O. C.; DECHEN, A. R. Critérios alternativos para diagnose foliar. In: SIMPÓSIO AVANÇADO DE QUÍMICA E FERTILIDADE DO SOLO, 1986, Piracicaba. Anais... Piracicaba: Fundação Cargill, 1986.

COMISSÃO DE FERTILIDADE DO SOLO DO ESTADO DE MINAS GERAIS. Recomendações para o uso de corretivos e fertilizantes e Minas Gerais: $4^{a}$ aproximação. Lavras, $1989.176 \mathrm{p}$.

GARCIA, A. W. R. Retirada de nutrientes pela produção do cafeeiro: cultivares Mundo Novo, Catuaí e Catimor. In: CONGRESSO BRASILEIRO DE PESQUISAS CAFEEIRAS, 8., 1980, Campos do Jordão. Resumos... Rio de Janeiro: IBC/GERCA, 1980. p. 3-6.

MALAVOLTA, E. Fertilização do cafeeiro sob alta densidade de plantio. In: SIMPÓSIO INTERNACIONAL SOBRE CAFÉ ADENSADO, 1994, Londrina. Anais... Londrina: IAPAR, 1996. p. 107-128.
MARTINEZ, H. E. P.; CARVALHO, J. G.; SOUZA, R. B. Diagnose foliar. In: COMISSÃO DE FERTILIDADE DO SOLO DO ESTADO DE MINAS GERAIS. Recomendações para o uso de corretivos e fertilizantes em Minas Gerais: 5 a aproximação. Viçosa, 1999. p. 143-170.

MARTINEZ, H. E. P.; SOUZA, R. B. de; ALVAREZVENEGAS, V. H.; MENEZES, J. F. S.; NEVES, Y. P.; OLIVEIRA, J. A. de; ALVARENGA, A. de P.; GUIMARÃES, P. T. G. Nutrição mineral, fertilidade do solo e produtividade do cafeeiro nas regiões de Patrocínio, Manhuaçu, Viçosa, São Sebastião do Paraíso e Guaxupé. 2. ed. rev. e aum. Belo Horizonte: Epamig, 2004. 60 p. (Boletim técnico, 72).

MATIELLO, J. B.; SANTINATO, R.; MIGUEL, A. E.; PAULINO, A. J.; PAULINI, A. E.; STEVANATO, S. G.; BRAGANÇA, J. B.; BARROS, U. V.; AMARAL, A. S.; RUSSO, A. F. A moderna cafeicultura de montanha. Rio de Janeiro: MAARA/PROCAFÉ, 1994. 22 p.

PAVAN, M. A.; CHAVES, J. C. D. A produção de café em função da densidade de plantio, adubação e tratamento fitossanitário. Turrialba, San José, v. 44, n. 4, p. 227-231, 1994.

PAVAN, M. A.; CHAVES, J. C. D. Influência da densidade de plantio de cafeeiros sobre a fertilidade do solo. In: SIMPÓSIO INTERNACIONAL SOBRE CAFÉ ADENSADO, 1994, Londrina. Anais... Londrina: IAPAR, 1996. p. 87-106.

PEREIRA, J. B. D. Eficiência nutricional de nitrogênio e de potássio em plantas de café (Coffea arábica L.). 1999. 99 f. Tese (Doutorado em Fitotecnia) - Universidade Federal de Viçosa, Viçosa, 1999.

RENA, A. B.; MAESTRI, M. Fisiologia do cafeeiro. In: RENA, A. B.; MALAVOLTA, E.; ROCHA, M.; YAMADA, T. (Eds.). Cultura do cafeeiro: fatores que afetam a produtividade. Piracicaba: Associação Brasileira para a Pesquisa da Potassa e do Fosfato, 1986. p. 14-85.

RENA, A. B.; NACIF, A. P.; GUIMARÃES, P. T. G.; BARTHOLO, G. F. Plantios adensados de café: aspectos morfológicos, ecofisiológicos, fenológicos e agronômicos. Informe Agropecuário, Belo Horizonte, v. 19, n. 193, p. 6170, 1998. 
SANTOS, E. H. Comparação entre análise química do solo de café adensado e do café normal: orientação aos agricultores sobre a melhor forma de se obter maior produtividade. In: CONGRESSO BRASILEIRO DE PESQUISAS CAFEEIRAS, 25., 1999, Franca, SP. Resumos dos Trabalhos Apresentados... Rio de Janeiro: MAA/ PROCAFÉ/PNFC, 1999. p. 110-111.

SOUZA, C. A. S.; GUIMARÃES, P. T. G.; CORREA, J. B.;

DIAS, F. P. Efeitos de doses de zinco via solo, em três cultivares de cafeeiro (C. arabica L.). In: CONGRESSO BRASILEIRO DE PESQUISAS CAFEEIRAS, 23., 1997, Manhuaçu, MG. Resumos dos Trabalhos Apresentados... Rio de Janeiro: MAA/PROCAFÉ/PNFC, 1997. p. 110-111.

SOUZA, R. B. Níveis críticos de enxofre em solos e folhas de cultivares de café. 1999. $88 \mathrm{f}$. Tese (Doutorado em Fitotecnia) - Universidade Federal de Viçosa, Viçosa, 1999. 